\title{
Historia de la Asociación Centroamericana de Anatomía (1965-2014)
}

\author{
History of the Central American Association of Anatomy (1965-2014)
}

Manuel Francisco Sigarán-Ramírez ${ }^{1,3}$; Rolando Cruz-Gutiérrez ${ }^{1,3,4,5}$, Álvaro Yglesias-Vieto ${ }^{1,3}$ \& Ricardo Losardo $^{2,4,5}$

SIGARÁN-RAMÍrEZ, M. F.; CRUZ-GUTIÉRREZ, R.; YGLESIAS-VIETO, Á. \& LOSARDO, R. Historia de la Asociación Centroamericana de Anatomía (1965-2014). Int. J. Morphol., 36(3):1130-1133, 2018.

RESUMEN: Se realizó una reseña histórica de la Asociación Centroamericana de Anatomía, describiendo sus orígenes, fundación, objetivos, requisitos para su ingreso y congresos realizados en el cincuentenario de su existencia.

PALABRAS CLAVE: Anatomía; AsociaciónCentroamericana de Anatomía; Historia.

\section{INTRODUCCIÓN}

La "Asociación Centroamericana de Anatomía" (ACA), fundada en 1965, fue la primera asociación de Anatomía que reunió a varios países en el continente americano. Un año después, en julio de 1966, se fundó la "Asociación Panamericana de Anatomía" (APA), cuyo mentor fue el Prof. Dr. Liberato Di Dío, logrando la expresión máxima de integración continental. Debemos señalar que fue en julio de 1964, en el Río de La Plata donde se creó la primera sociedad de anatomía que reunía a dos países del continente americano, Argentina y Uruguay: la "Sociedad Rioplatense de Anatomía", cuyos mentores fueron los Prof. Dres. José Luis Martínez y Alfredo Ruiz Liard.

Este fenómeno se debió a la necesidad de estimular el desarrollo y el mejoramiento de la docencia y la investigación de la Anatomía que sintieron los colegas, que fue un motor común en la década del sesenta que no tuvo fronteras en América.

En el 2012, en el congreso realizado en San José de Costa Rica ya se había instalado la idea entre los asistentes de ampliar la denominación e incluir a la región del Caribe, teniendo en cuenta la activa y reiterada participación de los países de República Dominicana, Cuba y Puerto Rico.
En el 2014, en el Congreso de Anatomía en Managua, Nicaragua, con el respaldo de la "Asociación Panamericana de Anatomía” y la "Academia Panamericana de Anatomía”, por impulso de dos de los autores de este artículo, los doctores Rolando Cruz Gutiérrez y Ricardo Losardo, se incorporó a la región del Caribe a esta Asociación, cambiándose la denominación por la de "Asociación Centroamericana y del Caribe de Anatomía” (ACyCA). Esta decisión fue confirmada y aprobada en la Asamblea del congreso del año siguiente realizada en San José de Costa Rica, donde además se aprobó el nuevo estatuto.

La aparición reciente de una copia documental histórica de la fundación de la Asociación Centroamericana de Anatomía de la década de los años sesenta nos induce a relatarla ahora y recordar la trayectoria de estos cincuenta años de existencia.

\section{Orígenes y fundación}

Esta organización anatómica nació como idea en Nueva Orleans, Louisiana, Estados Unidos de América en febrero de 1962, cuando terminaban el ciclo de Anatomía de posgrado, los profesores: Dr. Manuel Sigarán Ramírez

\footnotetext{
${ }^{1}$ Universidad de Costa Rica (UCR), San José, Costa Rica.

${ }^{2}$ Universidad del Salvador (USAL), Buenos Aires, Argentina.

${ }^{3}$ Miembro fundador de la Asociación Centroamericana de Anatomía.

${ }^{4}$ Miembro honorario de la Asociación Centroamericana y del Caribe de Anatomía.

${ }^{5}$ Presidente honorario de la Asociación Panamericana de Anatomía y Co-presidente de la Academia Panamericana de Anatomía.
} 
de la Universidad de El Salvador, Dr. José Ramiro Rivera $(\dagger)$ de la Universidad de San Carlos de Guatemala y el Dr. Rolando Cruz Gutiérrez de la Universidad de Costa Rica, que se comprometieron a promover esta idea en sus respectivos países.

Esta iniciativa se le informó a varios miembros del Departamento de Anatomía de la Escuela de Medicina de la Universidad del Estado de Louisiana (LSU) en Nueva Orleans, a quienes les pareció excelente, en especial a los doctores Charles Mayo Goss (1899-1981), Marilyn Zimny (1927-2006), Frank Low (1911-1998) y George W. D. Hamlett (1900-1975), de quienes tenemos excelentes recuerdos por sus condiciones humanas y profesionales, todos ellos con un gran dominio de la anatomía, la embriología y la histología.

El primer Jefe de Departamento de Anatomía en adherirse fue el Dr. Fabio Rosabal Conejo, de Costa Rica, quien lo hizo inmediatamente, en el mismo febrero de 1962.

$\mathrm{Al}$ año siguiente se continuó con el proyecto. En febrero de 1963 y en el Departamento de Anatomía de la Universidad de Costa Rica se reiteró el compromiso. Se adhirió el Prof. Dr. Álvaro Yglesias Vieto de la Universidad de Costa Rica; posteriormente y de la misma Universidad, el Dr. Álvaro Gómez de la Torre, el Dr. Félix Mata Bonilla (†), el MSc. Roberto Suárez Garcés (†), el Dr. Eduardo Grillo Bustamante $(\dagger)$, el Dr. Álvaro Fonseca Solórzano $(\dagger)$, el Dr. Pedro Morera Villalobos $(\dagger)$, también morfólogos formados en la Universidad de Louisiana, en Estados Unidos de América. El Dr. Manuel Sigarán Ramírez obtuvo el respaldo del Jefe del Departamento de Anatomía de la Facultad de Medicina de la Universidad de El Salvador, el Dr. Juan Héctor Berríos.

El 7 de diciembre de 1963, en El Salvador, durante el "X Congreso Médico Centroamericano y IV Latinoamericano de Anatomía Patológica" se redactó una carta con los interesados presentes en dicho evento. No hay documentación correspondiente.

En 1964 se había remitido a los Departamentos de Anatomía de sus Facultades de Medicina correspondientes de Costa Rica, El Salvador, Guatemala, Honduras, Nicaragua y Panamá, un formulario de invitación para sus profesores interesados en participar. Documento que conservamos (Formulario de invitación para participar de la fundación de la Asociación Centroamericana de Anatomía a los Jefes de Departamento de Anatomía de las Universidades estatales centroamericanas. Secretaria General, 1964).

En el mes de abril de 1964 se redactó un anteproyec- to de Estatuto de la Asociación Centroamericana de Anatomía (ACA), por su Secretario General Provisional, que fue presentado, discutido y aprobado en una sesión extraordinaria de la última semana de mayo de 1964 para someterlo en un próximo congreso a la eventual aprobación de todos los interesados. Documento que conservamos (Anteproyecto de Estatuto de la Asociación Centroamericana de Anatomía. Secretaria General, 1964).

Algunos colegas entusiasmados con este proyecto se constituyeron como el Comité Organizador y en condición de Presidente provisional se designó al Dr. Juan Héctor Berríos y como Secretario General de la ACA, al Dr. Manuel Francisco Sigarán Ramírez.

Se realizaron las gestiones con los Decanos de las Facultades de Medicina de las Universidades estatales Centroamericanas, así como con el Consejo Superior Universitario Centroamericano (CSUCA) (4) para obtener el reconocimiento de la Asociación y conseguir algún respaldo económico. Este solo se obtuvo como financiamiento parcial para un evento de la Oficina Panamericana de la Salud (OPS) y de la Facultad de Medicina de la Universidad del Estado de Louisiana (LSU).

La reunión se propuso para los días 11, 12 y 13 de octubre de 1965 en la Universidad de El Salvador con una invitación circular a las universidades del Istmo y hubo la respuesta del Director de la Facultad de Medicina de la Universidad Nacional Autónoma de México (UNAM), Dr. Donato G. Alarcón, excusándose de su asistencia por compromisos adquiridos previos, según documento del 27 de agosto de 1965 que conservamos.

El Prof. Dr. Manuel Sigarán Ramírez logró organizar con el Prof. Dr. Juan Héctor Berríos y el Prof. J. Ramón Alvarenga el "Primer Congreso Centroamericano de Anatomía" en la Universidad de El Salvador en 1965 y la Fundación de la "Asociación Centroamericana de Anatomía" durante ese evento.

\section{Objetivos de la asociación}

Los objetivos de la asociación enunciados en el estatuto fundacional eran:

a) Luchar por la superación científica y cultural de sus asociados.

b) Fomentar el estudio de la Anatomía en cada uno de los países centroamericanos. Tratar de unificar métodos de enseñanza e impulsar la investigación.

c) Respetar y proteger los derechos de sus miembros; actúa como elemento de defensa justificada. 
d) Servir de núcleo en el intercambio de conocimientos científicos y técnicos entre sus miembros, así como con otras sociedades similares.

e) Estrechar las relaciones con las Sociedades de Anatomía de otros países y promover el intercambio de personas.

Requisitos para su ingreso. Los requisitos para integrarla como asociado titular según el estatuto fundacional eran:

a) Haber obtenido el grado de Médico o un título equivalente a un doctorado en Ciencias Biológicas o en Anatomía.

b) Ser profesor activo de una Universidad centroamericana.

c) Tener por lo menos dos años de docencia universitaria en Anatomía debidamente comprobada.

d) hacer solicitud por escrito, debiendo ésta ser aprobada por la mayoría de los miembros de la asociación.

También existían las categorías de asociados fundadores, honorarios y correspondientes. Estos últimos para aquellos que no residieran en Centroamérica (Estatuto de la Asociación Centroamericana de Anatomía. Secretaria General, 1965).

Congresos centroamericanos realizados. Durante 50 años y de manera irregular se efectuaron once encuentros en cuatro países: Costa Rica, El Salvador, Nicaragua y Guatemala. Todos estos congresos centroamericanos se han celebrado con asistencia de todos los países centroamericanos y por lo tanto ha sido de "hecho" y de "derecho".

I Congreso y Fundación: 11 al 13 de octubre de 1965. San Salvador, El Salvador.

Sede: Universidad de El Salvador, Facultad de Medicina, Departamento de Anatomía.

Presidente: Dr. Juan Héctor Berríos (Jefe de Departamento).

II Congreso: 5 al 8 de agosto de 1967. San José, Costa Rica. Sede: Universidad de Costa Rica, Facultad de Medicina, Departamento de Anatomía.

Presidente: Dr. Fabio Rosabal Conejo $(\dagger)$ (Jefe y fundador del Departamento).

III Congreso: 16 al 20 de julio de 1969. San Carlos, Guatemala. Coincidió con el viaje a la Luna, cumpliéndose la profecía maya el primer día del año maya, 16 de julio.

Sede: Universidad de San Carlos de Guatemala, Facultad de Medicina, Departamento de Anatomía.

Presidente: Prof. Dr. Manuel Ángel Aguilera (Jefe del Departamento)

IV Congreso: 9 al 15 de febrero de 1992. San José, Costa Rica. Coincidió con el "X Congreso Panamericano de Anatomía" y el V Centenario del descubrimiento de América.
Sede: Universidad de Costa Rica, Facultad de Medicina, Departamento de Anatomía.

Presidente: Dr. Rolando Cruz Gutiérrez.

V Congreso: 12 al 16 de febrero de 1996. San José, Costa Rica. Coincidió con el "XIII Simposio Internacional de Ciencias Morfológicas" (ISMS) en la Universidad de Costa Rica. Sede: Universidad de Costa Rica, Facultad de Medicina, Departamento de Anatomía.

Presidente: Dr. Rolando Cruz Gutiérrez.

VI Congreso: 24 al 28 de abril de 2007. San José, Costa Rica. Coincidió con el "XVI Congreso Panamericano de Anatomía" en la Universidad de Costa Rica. También se celebró el $40^{\circ}$ Aniversario de la Federación Internacional de Asociaciones de Anatomistas (FIAA-IFAA).

Sede: Universidad de Costa Rica, Facultad de Medicina, Departamento de Anatomía.

Presidente: Dr. Rolando Cruz Gutiérrez.

VII Congreso: 13 al 16 de abril de 2009. San José, Costa Rica. Coincidió con el "I Simposio Ibero-latino-americano de Terminología Anatómica, Histológica y Embriológica” (SILAT I) (1).

Sede: Universidad de Costa Rica, Facultad de Medicina, Departamento de Anatomía.

Presidente: Dr. Rolando Cruz Gutiérrez.

VIII Congreso: 26 al 30 de abril de 2010. San José, Costa Rica. Coincidió con el "SILAT III" y con la Fundación de la Academia Panamericana de Anatomía.

Sede: Universidad de Costa Rica, Facultad de Medicina, Departamento de Anatomía.

Presidido por: Dr. Rolando Cruz Gutiérrez.

IX Congreso: 2 al 4 de mayo de 2012. San José, Costa Rica. Coincidió con el "SILAT VIII".

Sede: Universidad de Costa Rica, Facultad de Medicina, Departamento de Anatomía.

Presidente: Dr. José Luis Quirós Alpízar (Jefe del Departamento).

X Congreso: 16 al 18 de julio de 2014. Managua, Nicaragua. Coincidió con el "SILAT X". Aquí se resolvió la ampliación y nueva denominación de la ACA como: "Asociación Centroamericana y del Caribe de Anatomía" (ACyCA).

Sede: Universidad Nacional Autónoma de Nicaragua (UNAN) en Managua, Facultad de Medicina, Departamento de Anatomía. (Fig. 1).

Presidente: Dra. Jamnyce Altamirano Carcache (Jefa del Departamento).

Sede: Universidad Nacional Autónoma de Nicaragua (UNAN) en Managua, Facultad de Medicina, Depto. de Anatomía. 
XI Congreso: 24 al 28 de agosto de 2015. San José, Costa Rica. Coincidió con el "SILAT XII" y con la fundación de la Academia Panamericana de Historia de la Medicina y del "Primer Congreso de la Academia Panamericana de Historia de la Medicina".

Sede: Universidad de Costa Rica, Edificio de Educación Continua de la Cuidad de la Investigación.

Presidente: Dr. Rolando Cruz Gutiérrez.
Presente. Actualmente los países que conforman ACyCA son: Costa Rica, Cuba, El Salvador, Guatemala, Honduras, Nicaragua y República Dominicana. Cuenta con setenta y cinco miembros titulares y ocho miembros correspondientes (de Argentina, Brasil, Chile, México y Perú). Su actual presidente es el Prof. Dr. Reinaldo Antonio Roque Gutiérrez (Sitio oficial de la Asociación Centroamericana y del Caribe de Anatomia: https://acyca.weebly.com).

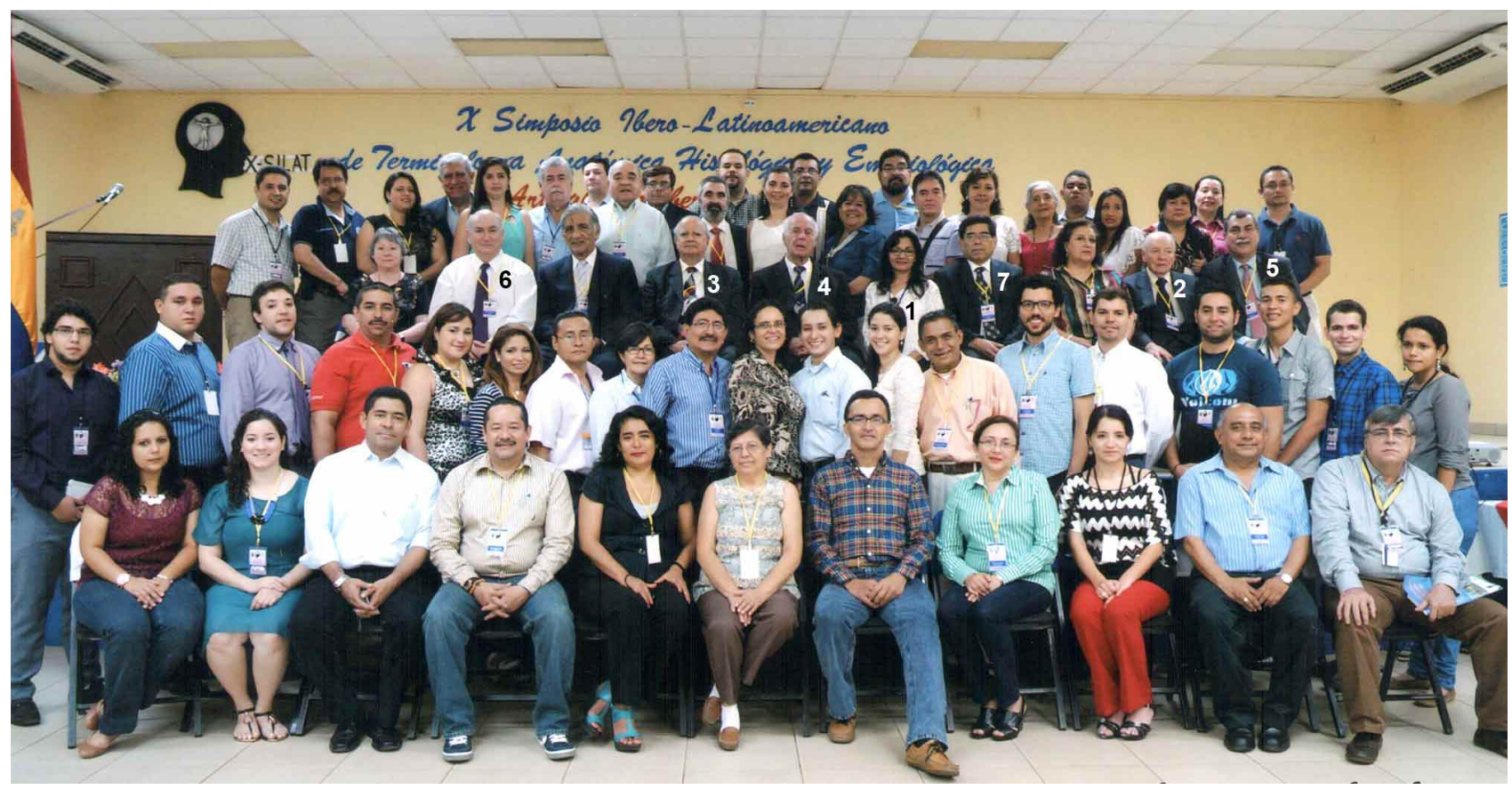

Fig. 1. Managua, Universidad Nacional Autónoma de Nicaragua (UNAN), Julio, 2014. Allí se impuso la nueva denominación de Asociación Centroamericana y del Caribe de Anatomía (ACyCA). En la fotografía se observan entre otros participantes a 1. Prof. Dra. Jamnice Altamirano, Presidente del X SILAT; a los Ex-Presidentes de la Asociación Panamericana de Anatomía: 2. Prof. Dr. Alberto Rodríguez Torres (1987-1990); 3. Prof. Dr. Rolando Cruz Gutiérrez (1992-1994 y 2007-2010); 4. Prof. Dr. José Carlos Prates (19982001); 5. Prof. Dr. Ricardo Jorge Losardo (2004-2007); 6. Prof. Dr. Mariano del Sol Calderón (2010-2013) y 7. Prof. Dr. Manuel Arteaga, actual Presidente de la Asociación Panamericana de Anatomía.

SIGARÁN-RAMÍREZ, M. F.; CRUZ-GUTIÉRREZ, R.; YGLESIASVIETO, Á. \& LOSARDO, R. History of the Central American Association of Anatomy (1965-2014). Int. J. Morphol., 36(3):1130-1133, 2018.

SUMMARY: A historical review of the Central American Association of Anatomy is made, describing its origins, foundation, objectives, requirements for its entry and congresses held in the fiftieth anniversary of its existence.

KEY WORDS: Anatomy; Association; Central America; History.

\section{REFERENCIAS BIBLIOGRÁFICAS}

Anteproyecto de Estatuto de la Asociación Centroamericana de Anatomía. Secretaria General, 1964.

Estatuto de la Asociación Centroamericana de Anatomía. Secretaria General, 1965.
Formulario de invitación para participar de la fundación de la Asociación Centroamericana de Anatomía a los Jefes de Departamento de Anatomía de las Universidades estatales centroamericanas. Secretaria General, 1964.

Losardo, R. J. Asociación Panamericana de Anatomía: reseña histórica y normativas vigentes. Int. J. Morphol, 27(4): 1345-1352, 2009.

Sitio oficial de la Asociación Centroamericana y del Caribe de Anatomía: https://acyca.weebly.com

Sitio oficial del Consejo Superior Universitario Centroamericano: http:// www.csuca.org

Dirección para correspondencia

Ricardo Losardo

Universidad del Salvador (USAL)

Buenos Aires

ARGENTINA

Recibido : 02-03-2018

Aceptado: 30-05-2018

Email: ricardo.losardo@usal.edu.ar 